$\begin{gathered}\text { EPiC Series in Education Science } \\ \text { Volume 1, 2017, Pages 489-495 }\end{gathered}$
$\begin{gathered}\text { AUBEA 2017: Australasian Universities Build- } \\ \text { ing Education Association Conference 2017 }\end{gathered}$

\title{
Appraising Constructive Alignment in a Construction Management Programme
}

\author{
Olubukola Tokede and Linda Tivendale \\ Deakin University, Australia. \\ olubukola.tokede@deakin.edu.au
}

\begin{abstract}
Construction Management (CM) programmes generally build on principles in traditional science and social-science disciplines creatively applied to the construction sector. In the last two decades, there has been significant growth in the number of universities in Australia and UK, offering construction management programmes. Despite these trends, there has been dearth of studies that investigate the alignment of the curriculum content with assessment requirements in construction management subjects. This study appraises the issues pertaining to constructive alignment in construction management programmes delivered in the higher education sector. This work provides an ethnographic insight on the perceived benefits of Constructive Alignment in relation to academic performance, student experience, and student-satisfaction in the UK. Future work will compare outcomes in constructively aligned courses in other academic institution. This work also suggest best practices for implementing constructive-alignment in the delivery of built environment courses.
\end{abstract}

\section{Introduction}

The origins of Construction Management programmes in universities date back to the mid1960 (Langford and Hughes, 2009). It is however worthy of mention that newer universities seem to be on the frontiers of advancing and delivering construction management programmes. The earliest harbingers of construction management were University of Manchester Institute of Management and Technology (UMIST), now part of the University of Manchester, UK. The ARCOM Conference in 2016, paid tribute to the role of UMIST in starting out the CM discipline, in its keynote address at Manchester titled "getting back to the roots".

Since its inception, the attractiveness of the construction management programme has soared immensely amongst new graduates of different disciplines. It is not unusual to have graduates of political science, business management, and even electrical engineering enrol in postgraduate 
construction management courses. Actually, many of these universities in the UK, and even Australia, introduced construction management as postgraduate degrees, and thus first-degree graduates of civil engineering, architecture, quantity surveying and building were often enticed by the prospects of a top-up degree that honed their managerial aptitude and enhanced their employability in a range of construction disciplines.

There have been many academic standards developed around the world to ensure the quality of construction management graduates. Newton (2011) reports on three threshold outcomes identified in Australian construction management programmes - judgement, self-development and communication. These generic practice skills are not exactly subject-specific, suggesting a need to establish the link between the curriculum content and the assessment requirements in construction management (CM) subjects. A number of stakeholders including government, construction industry, academia, professional bodies and associations (McArdle et al., 2012) influences the CM curriculum in many academic institutions especially in the more developed countries.

Newton (2016) argues that professional expertise in construction management requires normative discipline knowledge and professional experience. It may however be difficult to develop the needed 'aptitude' if the assessment requirements in construction management subjects are not closely connected to the curriculum content in institutions offering construction management programmes. Despite these trends, there has been dearth of studies that investigates the alignment of the curriculum content with assessment requirements in construction management subjects. Constructive alignment is a robust pedagogical framework to ensure that assessment in construction management subjects matches the 'taught elements' in the educational curriculum.

This paper appraises the theory of constructive alignment in the construction management discipline. This pilot study focuses mainly on the academic performance, student-satisfaction, and student-experience ratings of student cohorts enrolled in a construction management programme.

\section{Constructive Alignment (CA)}

According to Gajendran et al., (2014), constructive alignment (CA) is implicit in the design of educational courses and relevant across the spectrum of every intentional learning. Biggs (2011) explains that $\mathrm{CA}$ engages learners using meaningful learning activities, individual worldviews and experiences in understanding the world; to engage with new concepts and ideas. CA essentially draws upon the Personal Construct Theory, developed by Kelly (1955).

CA is essentially a bottom-up approach to the design and delivery of taught courses. There are two important schools of thought in CA. First of all, CA can be viewed as a framework for designing courses, as well as a heuristic for quality assurance in education providers (Biggs 2011). Neither of these perspectives are disparate and disconnected, rather they complement each other.

Morris (2008) found the CA-designed courses achieve higher mean marks and strong correlation between student-confidence and examination performance. It is however unclear whether this is the case in construction management subjects. Intuitively, the benefits of CA however seem apparent. McMahon and Thakore (2006) argued that CA accomplished greater standardization leading to fairer and more reliable assessment; greater transparency; more effective evaluation, greater coherence in programme of learning and enhanced student engagement. 
The Action Research - Reflect $>>>$ Plan $>>>$ Apply $\gg>>>$ Evaluate, is the conceptual methodology that underpins Constructive Alignment. Action Research has been a well-understood and useful theory in Construction Management Research. According to Fellows and Liu (2015), Action Research involves the participation of researcher in a process in order to identify, promote and evaluate problems. In CA, this involves an intentional attention to the components of a courseassessment, teaching plans and schedules as well as teaching philosophy and practice.

\section{Construction Management Programmes}

Construction management (CM) programmes originated from different worldviews. Some higher education sector, considers the $\mathrm{CM}$ as an extension of the civil engineering degree, while some others, seem to view CM as more closely associated with the social-sciences. The implication of this worldview was that CM programme was delivered as an education, rather than a training (Langford \& Hughes 2009). This equally had an effect on the calibre of university teachers in CM. Many of whom mostly consisted of industry-accredited staff that had years of experience in a traditional construction role. In recent years, trends have shifted towards recruitment of staffs, with higher academic qualifications and in many instances, little or no industry experience (Forsythe \& Zou 2006). Going by the trend, it could be hypothesized that $\mathrm{CM}$ academics in the future seem better positioned for university appointments to have had an education rather than a training. Skinner (1984) describes education' as the residue of knowledge, that outlasts memory.

McNamara (1997) argues that CM graduates need to be adept in both the technical and soft skills, required in the construction industry. In addition, the content of $\mathrm{CM}$ programme potentially has economic implications for universities. For institutions viewing CM as a purely soft-discipline (socialscience) education programme, the learning medium are essentially class-based, and in some many cases, amenable to full-online delivery. However, other institutions that provide CM has a training often have hands-on components, that require students to be physically present at some point on the campus.

Many CM programmes are taken at postgraduate and undergraduate levels. In more recent years, $\mathrm{CM}$ has been combined with other traditional disciplines hence many universities across the world are starting to 'market' double-degree programmes such as Construction Management with Civil Engineering, Architecture, Project Management, and even Facilities Management. There is a possibility that in the future, CM courses will include energy simulation, value engineering, and business management, to retain its relevance in a highly competitive business landscape

The CM programme has also been significantly propped up by many industry-platforms. One of the most prominent construction management platforms was ARCOM, which started out in 1984. ARCOM has particular focus in promoting built environment education, and developing early-career researchers. The CIOB also has a similar role but tends to be more industry-focused unlike ARCOM. CIOB provides professional accreditations at different levels to construction professionals. The CSIRO is another supporting organisation of CM education. CSIRO is Australian national science agency, and performs similar role to the BRE in the UK. Other relevant institutions include the Construction Industry Council (CIC), Construction Industry Institute (CII), originally US-based but also replicated in Australia. Construction Industry Research and Information Association (CIRIA) is also UK-based but is committed to improvements in the construction sector. The CNBR - Co-operative Network of Building Researchers started out from Australia. The CNBR was initiated by Peter Edwards and Frederick Pretorius in an AUBEA conference in 1991. CNBR provided a platform for construction academic, researchers and practitioners to be involved in web-based communication. It is quite noteworthy that AUBEA has contributed to the dissemination of notable ideas in diverse field of disciplines. Other 
bodies that have inputs in the curriculum design of the CM discipline include the Royal Institution of Chartered Surveyors (RICS), Association of Project Management (APM), and Council of Heads of the Built Environment (CHOBE).

\section{Ethnography}

Ethnography has been used a method of research in education settings for over three decades (Gordon et al., 2001). The scope of areas used in ethnographic initiatives include social interaction research, cultural studies, feminism, diversity, and materialist approaches. The predominant ethnographic educational research are ethnomethodology, phenomenology and symbolic interactionism (Gordon et al., 2001). Ethnomethodology simply provides a platform to understand the principles for organising human cohort; and aims to define the concept and content of knowledge. Phenomenology deals with focus on specific events and activities, while symbolic interaction seeks to focus on the social norms that informs human behaviours.

According to Shipton and Hughes (2013), ethnographic research methods, are becoming more commonplace in Construction Management (CM) research. The ethnographic approach in the study is tailored after the phenomenology method and requires the observation of student behaviour, statements and body languages, to gain an insight into their motivations and issues. Ethnography is rooted in anthropology and requires an intense level of interaction between researcher and respondents (Fellows and Liu, 2015). Data was collected over 20 hours of observations, 5 interviews and feedback surveys. The Ethnographic studies took place over a period of three months in the UK university. There was a 2-hour weekly interaction at the UK University over an 11-week period truncated by an inter-semester break. There were only about twenty-two students participating in the interaction. The ethnographic interaction happened in the context of a class lecture and therefore secured the voluntary participation of students.

The researcher also obtained comments from the routinely conducted student-satisfaction survey to further validate the perception of students. The broad categories of satisfaction examined in this study were centered on quality of teaching, assessment and feedback, academic support, organisation and management, learning resources, personal development and overall satisfaction.

The purpose of the ethnographic study was to gain insights into the efficacy of the construction alignment method. The ethnographic procedure is however steeped in subjectivism, and interpretations by the researcher could be misconstrued. The data was collected and analysed based on the emic and etic orientations, as described by Fetterman (2010)

\section{Discussion}

The information obtained from the ethnographic interaction revealed the efficacy of constructive alignment on crucial learning outcomes of students. This work assesses the impact of constructive alignment on three student outcomes that are arguably the concern of many higher education institutions - Student Experience, Student Performance and Student Satisfaction. Although, there are many other student-outcomes, however, this three student-outcomes are central to the attraction and retention of students, by higher education sectors. This outcomes have also been recognised by many academic platforms in construction 


\subsection{Student Experience}

Constructive Alignment has potentials to enhance the student experience (Biggs 2011), and students enrolled in construction management programmes are no exception. While there are other issues such as employability, professional expertise, communication and digital awareness, this study simply addresses student-oriented issues such as flexibility, industry-awareness, development, and rigour. The dominant cohort in many construction-management programmes at postgraduate level tend to be international students. However, many institutions rarely incorporate some form of 'internationalisation' in the construction management curriculum (Wang et al. 2010). This often diminishes the quality of student experience. However, many students also appreciate the level of exposure, accountability and engagement of western-styled education, and this often results in an overall excellent performance.

\subsection{Academic Performance}

Students in the UK University investigated attained an average mark of $78 \%$, with the least score being $48 \%$, and the highest score being $92 \%$. Marks attained by students have been closely correlated to student-satisfaction levels. In addition, good marks has been found to enhance the self-esteem of students (Baumeister et al. 2003). Given the spate of mental health issues in the higher educational sector (Hill 2012), it becomes important to recognise and understand the need for sustained but deserved academic performance of students. In this study, it was found that constructive alignment, helps to bridge the nexus between the expectations of students, and the intentions of tutors. The assessment in the CM programme also serve as a medium of communicating and justifying the learning outcomes and the specific aptitude developed in individual units or courses. Biggs and Tang (2007) had previously stated that emphasis on student performance was critical to the CA approach.

\subsection{Student-Satisfaction}

According to Forsythe and Zou (2006), student-satisfaction are often measured via standard survey instruments. More recently, a number of universities have adopted electronic means of administering surveys in order to reflect more genuineness, transparency and accountability. However, electronicallyadministered surveys are prone to low responses, and could be less-popular compared to paper-based surveys, where captive audiences may be readily inclined to provide instantaneous responses on their experiences and expectations. Regardless of the survey mechanism, Carrol (2016) reported an overall satisfaction of over $75 \%$ in Construction Management courses, a marked improvement from the situation 10 years ago. The study also found that student enrolled in constructively-aligned subjects may be inclined to higher dissatisfaction levels, compared to cohorts in non-constructively aligned subjects The possible explanation for this, is that constructive alignment may be viewed as tick-boxes to the delivery of education, and hence student satisfaction could stem from a 'mismatch' between what was promised in the courses, and what was achieved. A classic case of 'over-promising' and 'underdelivering'. In the ethnographic study, it was found that 'Constructive alignment' (CA) has the benefit of enhancing accountability between staff and student. However, CA could make students more vulnerable to dissatisfaction. For instance, students in constructively-aligned subjects often muttered that "this was not expressly requested in the assignment brief". Another common comment in this study, was that "taught content may not match the assignment". Constructive Alignment thus have the potential of placing knowledge into set boxes, and intensifies the focus of students on assessment, an observation consistent with customer-oriented learning (Boud \& Falchikov 2006). In this study, the student cohort investigated attained a student-satisfaction level of over $80 \%$ in the CM subject investigated. However, some comments were made regarding the areas of improvement in the unit. 


\section{Conclusion and Future Trends}

CM programmes are popular amongst new graduates seeking for a career in the construction industry. However, there not much has been done in reconciling the student-outcomes and the design of construction management curriculum. This study appraises three key student outcomes - student experience, academic performance and student satisfaction, based on an ethnographic study in a UK university. The paper advocates for constructive alignment in better responding to student-needs, and developing a more fit-for-purpose curriculum for construction management education.

The work however suggests that CA needs to take into cognisance, the input of students in designing courses, and also involve educational stakeholders, at all levels. Student-satisfaction levels in CM programmes are relatively high. However, this can still be enhanced through strategic implementation of CA, taking into cognisance the needs of CM students, who are in search of flexibly, industry-oriented and relevant knowledge that holds potential to enhance their employability in a highly competitive business environment.

\section{References}

Baumeister, RF, Campbell, JD, Krueger, JI \& Vohs, KD 2003, 'Does high self-esteem cause better performance, interpersonal success, happiness, or healthier lifestyles?', Psychological science in the public interest, vol. 4, no. 1, pp. 1-44.

Biggs, J \& Tang, C 2007, 'Teaching for quality learning at university (Society for research into higher education)'.

Biggs, JB 2011, Teaching for quality learning at university: What the student does, McGraw-Hill Education (UK).

Boud, D \& Falchikov, N 2006, 'Aligning assessment with long - term learning', Assessment \& Evaluation in Higher Education, vol. 31, no. 4, pp. 399-413.

Carrol, D 2016, Graduate Course Experience 2015, Melbourne VIC.

Fellows, RF \& Liu, AM 2015, Research methods for construction, John Wiley \& Sons.

Fetterman, D. M. 2010. Ethnography: Step-by-step, Sage.

Forsythe, P \& Zou, PX 2006, 'Improving student satisfaction in undergraduate construction management studies', in Proc., Australian Universities Building Education Association Annual Conference.

Gajendran, T, Tang, P, Brewer, G, Hilaire, T, Ruddock, L, Amaratunga, D \& Haigh, R 2014, 'A Pedagogical Framework for Conceptualising the Design and Delivery of Construction Management Courses through 'Constructive Alignment', in 2014 CIB W55/65/89/92/96/102/117 \& TG72/81/83

International Conference on Construction in a Changing World. 
Gordon, T., Holland, j. \& Lahelma, E. 2001. Ethnographic research in educational settings, na

Hill, R 2012, Whackademia: An insider's account of the troubled university, NewSouth.

Kelly George, A 1955, The psychology of personal constructs: A theory of personality, New York: Norton.

Langford, D \& Hughes, W 2009, Building a discipline: the story of construction management, ARCOM.

McArdle, K., Gunning, J. G. \& spillane, J. P. 2012. Effectiveness of the construction management courses. Management, 167, 176.

McMahon, T \& Thakore, H 2006, 'Achieving constructive alignment: putting outcomes first', Aukštojo mokslo kokybe, no. 03, pp. 10-9.

McNamara, E, Howarth, T, Hill, C \& Stoneman, G 1997, 'Mentoring construction graduates: Bridging the gap between academia and industry', in 13th Annual ARCOM Conference, pp. 15-7.

Morris, MM 2008, 'Evaluating university teaching and learning in an outcome-based model: Replanting bloom'.

Newton, S. 2011. Learning and Teaching Academic Standards Project-Building and Construction Learning and Teaching Academic Standards Statement. OLT, Sydney.

Newton, S. 2016. The being of construction management expertise. Construction Management and Economics, 34, 458-470.

Shipton, C., Hughes, W.,2013. Making changes in practice: an ethnographic study of a hospital project. Editors: Smith, S. \& Ahiaga-Dagbui, D , Proceedings of the 29th Annual ARCOM Conference, Association of Researchers in Construction Management, Reading, MA, 2013. 1113-1123.

Skinner, BF 1984, 'The shame of American education', American Psychologist, vol. 39, no. 9, p. 947.

Wang, G, Lu, H \& Ren, Z 2010, 'Globalisation in construction management education', Journal of Applied Research in Higher Education, vol. 2, no. 2, pp. 52-62. 